\title{
TEACHING INTERVENTION TO ENHANCE HIV INFECTION AWARENESS IN A BIOMEDICAL SCIENCE DEGREE
}

\author{
A. Peña-Fernández ${ }^{1}$, M.A. Peña ${ }^{2}$, J.B. Escalera ${ }^{2}$ \\ ${ }^{1}$ De Montfort University, School of Allied Health Sciences (UNITED KINGDOM) \\ ${ }^{2}$ Universidad de Alcalá, Departamento de Ciencias Biomédicas (SPAIN)
}

\begin{abstract}
Condom use remains the predominant prophylactic intervention to control rates of human immunodeficiency virus (HIV) infection. However, chemoprophylactic strategies, which involve preexposure prophyaxis (PrEP) and post-exposure prophyaxis (PEP), have emerged as appropriate prevention tools to minimise and prevent future infections. Different studies have indicated that PrEP can prevent new HIV infections among men who have sex with men when used daily or event-based, and it is also effective with heterosexuals and people who inject drugs. However, appropriate education is needed as recent reports have observed a decline in adherence to PrEP over time, particularly in young adults, which will impact on the effectiveness of PrEP. Thus, we created a brief educational short intervention (3 hours) to increase the awareness of HIV with second year BMedSci Medical Science (Hons) students at De Montfort University (DMU, UK) in 2016/17 (Peña-Fernández et al., 2017) [1]. Briefly, BMedSci students tailored a community-centred intervention programme to reduce HIV infection rates following evidence-based public health methodology. $92 \%$ indicated an acquisition of knowledge for preventing HIV transmission and tools to fight this disease. However, BMedSci students also showed a lack of knowledge of preventative measures (PrEP and PEP), routes of transmission and appropriate screening. We implemented a similar teaching strategy with BSc Biomedical Science (BMS) students enrolled in the level 4 module of Basic Microbiology in 2017/18, but limited to two hours: one-hour lecture and one hour workshop in which different HIV prevention strategies were discussed and analysed by students. BMS students were also provided with an overview about the Joint United Nations Programme on HIVIAIDS (UNAIDS) 90:90:90 targets in the UK (2016, [2]). In a similar way as with the BMedSci cohort, BMS students showed little awareness about PEP/PrEP, specifically knowledge about what they are/how they work, access and usage. This teaching intervention was well-received by students according to the feedback provided in the final module level feedback. BMS participants ( $n=27$ out of 187 students) indicated that they enjoyed the session and suggested a practical session and the introduction of case studies to enhance the teaching intervention. We are developing a virtual clinical case study on HIV following recent successful experiences in the development and introduction of these novel learning strategies and have performed small modifications in the delivery of this workshop for 2018/19 to increase engagement and interaction. In conclusion, we consider that similar short education interventions that specifically target HIV chemoprophylaxis would be needed in any degree to prevent the decline in adherence to PrEP over time observed in young adults and reduce PEP/PrEP stigma and other barriers which could impede their access.
\end{abstract}

Keywords: HIV, chemical prophylaxis, PrEP, preventive education.

\section{INTRODUCTION}

Human immunodeficiency virus (HIV) is a Lentivirus, a genus of the family Retroviridae that causes HIV infection and over time, without the appropriate treatment, can develop into acquired immunodeficiency syndrome (AIDS) in the infected patient. AIDS is the most severe manifestation resulting from progressive immunosuppression induced by HIV. To date, there are two HIV species, named HIV-1 and HIV-2, HIV-1 is the major species.

The Joint United Nations Programme on HIVIAIDS (UNAIDS) launched in December 2013 an ambitious treatment target, known as UNAIDS 90:90:90 targets, to achieve epidemic control by 2020 [3]. This treatment target consisted of achieving by 2020 the following targets: $90 \%$ of people living with HIV will know that they are infected; $90 \%$ of them will be receiving sustained antiretroviral therapy; and $90 \%$ of them will have achieved viral suppression [4].

More than three decades after the first identification of AIDS in the United States, a decline in new HIV diagnoses among men that have sex with men (MSM) has been observed in five London (UK) clinics 
[5]. Moreover, the UNAIDS 90:90:90 targets were met for the first time in London in 2016, and were similar for the whole of England except for the figure for people living with diagnosed HIV infection, which was below the target (88\%) [5]. However, the European Centre for Disease Prevention and Control (ECDC) has recently reported that the proportion of undiagnosed HIV among MSM remains below the target in six European countries [6].

Although condom use remains the cornerstone of prophylactic intervention to control rates of HIV infection, there is no a single prevention method or intervention that can combat the HIV epidemic globally on its own due to the heterogeneity of HIV epidemic [7-8]. Thus, the use of antiretroviral drugs as prophylactic agents (chemoprophylaxis), which consists of pre-exposure prophyaxis (PrEP) and post-exposure prophyaxis (PEP), are being recommended to reduce HIV transmission [9]. However, adherence to the specific regimen of any of these chemoprophylaxis methods and sexual behaviour is crucial for their preventive efficacy and to avoid other sexual transmitted diseases. Notwithstanding, different studies have reported that the awareness for these drug-based preventive methods, specifically for PrEP, is low [9].

In a similar way, we observed a general lack of awareness in chemoprophylaxis methods in our second year BMedSci Medical Science students at De Montfort University (DMU, Leicester, UK) during the introduction of a short pedagogic intervention to increase HIV awareness in 2016/17 [1]. The main aim of this paper was to implement a similar teaching strategy in our Biomedical Science (BMS) undergraduate programme to increase knowledge of preventative measures (specifically PrEP and PEP), routes of HIV transmission and appropriate screening, and to determine its effectiveness.

\section{METHODOLOGY}

We performed a series of curriculum modifications in "Basic Microbiology" in 2016/17, by expanding the module to 30 credits and adding topics related to important groups of pathogens for BMS students including viruses, which resulted in a significant increase in students' satisfaction [10]. In the 2017/18 course, we introduced a specifically designed two-hour long teaching strategy to increase HIV awareness in this module of Basic Microbiology following the methods described in Peña-Fernández et al. (2017) [1], but with some modifications as follows: one-hour lecture on what viruses are and HIV including an overview of the UNAIDS 90:90:90 targets in the UK; and one hour workshop, in which students, working in small groups, were asked to identify different community-centred interventions to reduce HIV infection rates in Leicester following evidence-based public health methodology. Interventions were discussed with the rest of the class and the academic lead who identified weaknesses and suggested improvements. Feedback related to this teaching intervention was collected through two specific questions in the module level feedback. Ethical approval was provided by the Research Ethics Committee at DMU (Ref. 1729) to use this feedback in this pedagogic study.

\section{RESULTS}

The short teaching intervention to increase HIV awareness was well-received by BMS students according to the feedback provided. 27 out of 187 students completed the module level feedback (MLF), and indicated that they enjoyed the session and suggested a practical session and the introduction of case studies to enhance the teaching intervention. A minor proportion of students completed the MLF maybe because it was delivered by the Faculty in April 2018 when students were completing their revision for their main exam, scheduled early in May; students were advised about the MLFs by email). Some examples are depicted in Table 1, as positive and negative and/or suggestions for improvement. In a similar way as BMedSci students, BMS student showed a general lack of awareness in PrEP and PEP methods, and were unaware that Leicester was one of the participating cities in the PrEP Impact Trial programme carried out by Public Health England and National Health Service (NHS) England since 2017 (more information available at: http://www.tradesexualhealth.com/sexual-health/pep-prep.html). Unfortunately, we were unable to record their knowledge of HIV preventative measures, routes of HIV transmission and screening using the feedback-questionnaire used with BMedSci students because of a lack of time. 
Table 1. Example of positive and/or suggestions for improving the session on HIV awareness.

\begin{tabular}{|c|c|}
\hline Type & Response \\
\hline Positive & $\begin{array}{l}\checkmark \quad \text { I did find the HIV lecture interesting and helpful to my studies. } \\
\checkmark \quad \text { I enjoyed the HIV lecture as it gave me a further insight into more } \\
\text { knowledge about HIV in which I did not know about. } \\
\checkmark \quad \text { I enjoyed the HIV lecture. I feel there should be more lectures of HIV } \\
\text { awareness. } \\
\checkmark \quad \text { I have enjoyed the session as I thought it provided really important } \\
\text { information about prevention of HIV and also ways to treat it and detect it } \\
\text { early. } \\
\checkmark \text { This lecture was very good and doesn't need to be improved. } \\
\checkmark \text { I enjoyed it very much. }\end{array}$ \\
\hline $\begin{array}{c}\text { For } \\
\text { improvement }\end{array}$ & $\begin{array}{l}\checkmark \text { Practical sessions would increase HIV awareness instead of lectures. } \\
\checkmark \quad \text { I found the HIV lecture very interesting. I would have like more time to get } \\
\text { my head around each disease due to how complex each is. } \\
\checkmark \quad \text { I have enjoyed it, but if I may suggest something, it will be also a bit talk } \\
\text { about other viruses. } \\
\checkmark \text { The HIV lecture was okay, the structure of the presentation wasn't } \\
\text { cohesive or in order. Needs more information about the disease than } \\
\text { statistics. Case studies would be a good addition to the lectures too. }\end{array}$ \\
\hline Non-re & $\begin{array}{l}\checkmark \quad \text { I found learning about the diseases was a lot more challenging than some } \\
\text { of the other modules. }\end{array}$ \\
\hline
\end{tabular}

\section{FUTURE WORK}

We have taken into account BMS student feedback and we are performing the following changes to increase HIV awareness in these students:

- Modification of the workshop so students can tailor a community-centred intervention programme to reduce HIV infection rates rather than identifying applicable interventions displayed on the whiteboard. Students will be timetabled in small sessions and will be provided with easy to read scientific articles to identify interventions.

- Students will be asked to complete a virtual clinical case study on HIV available in the DMU eParasitology package. We will follow recent successful experiences from our team in the development and introduction of these case studies in other undergraduate and postgraduate programmes [11].

- Finally, we have also created an on-line unit for the learning and teaching of HIVIAIDS, which is accessible here: http://pathogens.dmu.ac.uk/units/hiv/story_html5.html (Fig. 1). The unit provides comprehensive information about the virology of the HIV viruses and a description of AIDS, current up-to-date data on the epidemiology of HIVIAIDS and ways for diagnosing, treating and preventing HIV infection. 


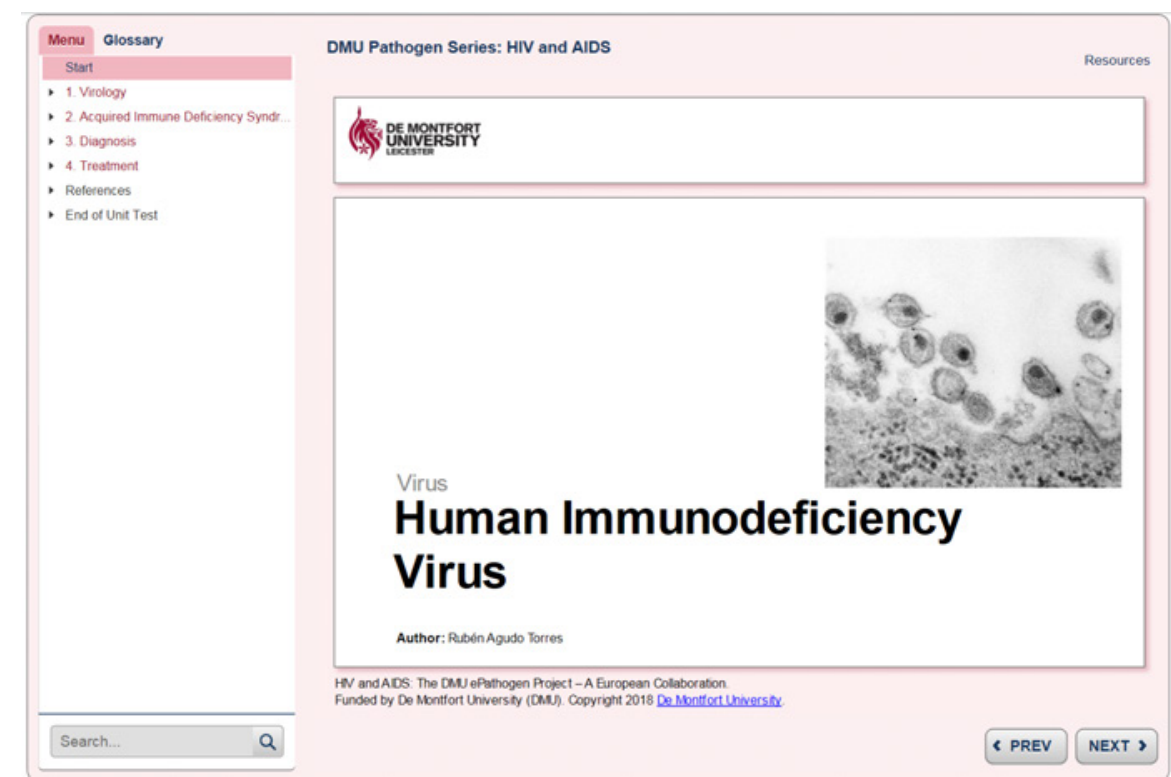

Figure 1. Overview of HIV elearning unit in the future DMU e-Pathogens (Image courtesy of DMU and USP-CEU University). Available at: http://pathogens.dmu.ac.uk/units/hiv/story_htm/5.html

\section{CONCLUSIONS}

Level 4 Biomedical Science students enjoyed the short intervention introduced this academic year, 2017/18, to enhance HIV awareness, and suggested a more practical/case study approach to study this important disease. In relation to acquisition of knowledge in these students, unfortunately our results are inconclusive due to the fact that we were unable to record their knowledge before and after this short teaching intervention. In conclusion, we consider that similar short education interventions that specifically target HIV chemoprophylaxis would be needed in any degree to prevent the decline in adherence to PrEP over time observed in young adults and reduce PEP/PrEP stigma and other barriers which could impede their access.

\section{ACKNOWLEDGEMENTS}

The authors would like to express their sincere appreciation to Jonathan Coope and Maxine Armstrong (DMU) for their work in software development of DMU e-Pathogens. Authors are in debt to the Teaching Innovation Project Fund at De Montfort University (scheme 2016-17) to fund this project, awarded to Dr. Peña-Fernández.

\section{REFERENCES}

[1] Peña-Fernández A., Peña MA., Evans MD. Introducing training related to the use of drugs to protect humans from HIV infection. ICERI2017 Proceedings 2017; 7123-7127. ISBN: 978-84697-6957-7.

[2] UNAIDS. 90-90-90 An ambitious treatment target to help end the AIDS epidemic. 2014, Joint United Nations Programme on HIVIAIDS. 2014.

[3] Doshi RH., Sande E., Ogwal M., Kiyingi H., McIntyre A., Kusiima J., Musinguzi G., Serwadda D., Hladik W. Progress toward UNAIDS 90-90-90 targets: A respondent-driven survey among female sex workers in Kampala, Uganda. PLoS One 2018; 13(9):e0201352.

[4] Habiyambere V., Dongmo Nguimfack B., Vojnov L., Ford N., Stover J., Hasek L., Maggiore P., Low-Beer D., Pérez Gonzàlez M., Edgil D., Williams J., Kuritsky J., Hargreaves S., NeSmith T. Forecasting the global demand for HIV monitoring and diagnostic tests: A 2016-2021 analysis. PLoS One 2018; 13(9):e0201341.

[5] Public Health England (PHE). Towards elimination of HIV transmission, AIDS and HIV-related deaths in the UK. PHE publications gateway number 2017572. 2017. 
[6] Brown AE., Attawell K., Hales D., Rice BD., Pharris A., Supervie V., Van Beckhoven D., Delpech VC., An der Heiden M., Marcus U., Maly M., Noori T. Monitoring the HIV continuum of care in key populations across Europe and Central Asia. HIV Med. 2018 May 8. doi: 10.1111/hiv.12603.

[7] Molina JM., Capitant C., Spire B., Pialoux G., Cotte L., Charreau I., Tremblay C., Le Gall JM., Cua E., et al. On-Demand Preexposure Prophylaxis in Men at High Risk for HIV-1 Infection. N Engl J Med 2015; 373(23):2237-46.

[8] Musyoki H, Bhattacharjee P, Blanchard AK, Kioko J, Kaosa S, Anthony J, et al. Changes in HIV prevention programme outcomes among key populations in Kenya: Data from periodic surveys. PLoS ONE 2018; 13(9): e0203784.

[9] Dolezal C., Frasca T., Giguere R., Ibitoye M., Cranston RD., Febo I., Mayer KH., McGowan I., Carballo-Diéguez A. Awareness of Post-Exposure Prophylaxis (PEP) and Pre-Exposure Prophylaxis (PrEP) Is Low but Interest Is High Among Men Engaging in Condomless Anal Sex With Men in Boston, Pittsburgh, and San Juan. AIDS Educ Prev 2015; 27(4):289-97.

[10] Peña-Fernández A., Torrado G., Agudo R., Peña MA. Additional curriculum modifications for enhancing the teaching of parasitology and infectious diseases at an English university. EDULEARN18 Proceedings 2018; pp. 7156-7161. ISBN: 978-84-09-02709-5.

[11] Peña-Fernández A., Magnet A., Peña MA. Focus group to create a virtual case study model unit for the DMU e-Parasitology. EDULEARN18 Proceedings 2018; pp. 7104-7108. ISBN: 978-8409-02709-5. 